\title{
A Review: Microbial Diversity and Function of Fermented Meat Products in China
}

\author{
Zhengli Wang, Zhengxi Wang, Lili Ji, Jiamin Zhang, Zhiping Zhao, Rui Zhang, Ting Bai, \\ Bo Hou, Yin Zhang, Dayu Liu, Wei Wang* and Lin Chen*
}

Key Laboratory for Meat Processing of Sichuan Province, Chengdu University, Chengdu, China

OPEN ACCESS

Edited by:

Wanping Chen,

Georg August University of Göttingen,

Germany

Reviewed by:

Dengyong Liu,

Bohai University, China

Lixin Luo,

South China University of Technology,

China

Xianchao Feng,

Northwest A \& F University Apple

Research Center, China

*Correspondence:

Wei Wang

wangwei8619@163.com

Lin Chen

chenlin@edu.edu.cn

Specialty section:

This article was submitted to

Food Microbiology,

a section of the journal

Frontiers in Microbiology

Received: 23 December 2020 Accepted: 30 April 2021

Published: 07 June 2021

Citation:

Wang Z, Wang Z, Ji L, Zhang J, Zhao Z, Zhang R, Bai T, Hou B, Zhang Y, Liu D, Wang W and Chen L (2021) A Review: Microbial Diversity and Function of Fermented Meat

Products in China.

Front. Microbiol. 12:645435. doi: 10.3389/fmicb.2021.645435
Fermented meat products have a long history in China. These products exhibit a characteristic unique flavor, compact meat quality, clear color, long shelf life and wide variety and are easy to transport. During the processing and storage of fermented meat products, microorganisms are present and exhibit diverse characteristics. Microorganisms can accelerate the degradation of proteins and fats to produce flavor compounds, inhibit the growth and reproduction of heterozygous bacteria, and reduce the content of chemical pollutants. This paper reviews the microbial diversity of Chinese ham, sausage, preserved meat, pressed salted duck, preserved fish and air-dried meat and provides analyses of the microbial compositions of various products. Due to the differences in raw materials, technology, auxiliary materials, and fermentation technology, the microbial species found in various fermented meat products in China are different. However, most fermented meat products in China are subjected to pickling and fermentation, so their microbial compositions also have similarities. Microorganisms in fermented meat products mainly include staphylococci, lactobacilli, micrococci, yeasts, and molds. The study of microbial diversity is of great significance for the formation of quality flavor and the safety control of fermented meat products, and it provides some theoretical reference for the study of fermented meat products in China.

Keywords: fermented meat products, microbial diversity, bacteria, fungi, function of microorganisms

\section{INTRODUCTION}

Fermented meat products are meat products with longer shelf lives and special flavors, textures and colors that are made of raw meat under specific temperature and humidity conditions by fermentation via microorganisms or enzymes (Liu Y. L. et al., 2020). Fermentation methods include natural fermentation and the artificial addition of a starter to regulate fermentation (Sivamaruthi et al., 2020). The microorganisms involved in the natural fermentation process are primarily derived from raw materials and the environment. Under specific curing and maturing process conditions, typical local microbial communities are formed through competition, thus significantly affecting the product quality and safety (Frédéric et al., 2006). In the 1990s, with the transformation of Chinese people's demand for meat from quantity to quality, fermented meat 
products with artificially added microbial starters were gradually introduced into the Chinese market (Yu et al., 2010).

Many traditional meat products, such as Sichuan preserved meat, Hunan preserved meat, Nanjing pressed salted duck, Cantonese sausage, Sichuan sausage, Jinhua ham, Xuanwei ham, and Rugao ham, are all fermented. In recent years, with the improvement of production technology and equipment, research on the flavor, sensory perception, nutritional characteristics and safety of fermented meat products has become a hot topic (Douglas et al., 2020). Microorganisms play an important role during the fermentation of meat products. Flavor formation in fermented meat products is a complex biochemical process that has not been completely understood to date. The microbial diversity of the primary fermented meat products in China is summarized in this paper, and the characteristics of their microbial compositions were analyzed to provide a theoretical basis for further study on fermented meat products.

\section{THE FUNCTION OF MICROORGANISMS IN FERMENTED MEAT PRODUCTS}

Food fermentation is not only an effective method of food preservation but also an economical method of food processing (He et al., 2017). Microorganisms play an important role in fermented meat products, and their functions are as follows:

Promotion of the production of special flavors in meat products (PaPamanoli et al., 2002; Polka et al., 2015). Studies have shown that Staphylococcus carnosus (S. carnosus) and Staphylococcus xylosus (S. xylosus) can significantly promote the hydrolysis of fat and protein in preserved meat, improve the color and promote the rapid formation of flavor (Zhou et al., 2018). The esterases, proteases and catalases produced by microorganisms have synergistic effects with endogenous enzymes, causing biochemical changes in the proteins and fats in raw meat and forming small molecules, such as amino acids, esters, peptides and short-chain volatile fatty acids. The digestive function is greatly improved, and the contents of essential amino acids, vitamins and bifidobacterium are increased, enhancing the effects on nutrition and health (Liang et al., 2010). Chen et al. (2017) inoculated Harbin dried sausage with a mixed starter, and the free fatty acid (FFA) content in the inoculated group was significantly higher than that in the uninoculated group. The peroxide value and thiobarbituric acid contents in the inoculated group were significantly reduced compared with those in the uninoculated group, and the contents of aldehydes, ketones and hydrocarbons, which are related to lipid oxidation, were significantly reduced compared with those in the uninoculated group. The mixed starter promoted the hydrolysis of fat, inhibited lipid peroxidation and improved the fermentation flavor of Harbin dried sausage. Wang et al. (2014) added complex microbial starters to traditional preserved meat, and the contents of free amino acids and the types of volatile flavor substances in the preserved meat increased, which improved its nutritional value, flavor and safety.

Inhibition of the growth and reproduction of heterozygous bacteria (Swetwiwathana and Visessanguan, 2015).
Microorganisms primarily inhibit the growth and reproduction of harmful bacteria through bacterial competition, acid production and bacteriocin production. Studies have shown that $S$. xylosus can inhibit the growth of Listeria monocytogenes ( $L$. monocytogenes) in sausage (PaPamanoli et al., 2002). Wang et al. (2013) inoculated Latilactobacillus sakei subsp. sakei (L. sakei) as a starter culture into Sichuan sausage, and the results showed that the lactic acid bacteria rapidly controlled the growth of the total bacterial colonies during sausage fermentation and inhibited the growth of foodborne pathogenic bacteria, such as Escherichia coli (E. coli) and enterobacteriaceae. Lactic acid bacteria can decompose carbohydrates in sausages to produce a large number of lactic acid and a small number of acetic acid as well as propionic acid, formic acid, 3-methyl-butyric acid, butyric acid and other organic acids, thus extending the shelf life of sausages (Li et al., 2015). Lactic acid bacteria can reportedly inhibit or kill spoilage microorganisms and pathogenic microorganisms in food (Zhang et al., 2017). Zhao et al. (2017) isolated and screened a strain of lactic acid bacteria with obvious antibacterial activity against E. coli and Staphylococcus aureus (S. aureus) from five kinds of fermented meat products, which was identified as Weissella hellenica ( $W$. hellenica). Studies have shown that L. sakei $\mathrm{C} 2$ can produce broad-spectrum antibacterial bacteriocins and inhibit the growth of harmful microorganisms (Gao et al., 2014).

Reducing the content of biogenic amines (BAs). Sun et al. (2016) found that six types of BAs (cadaverine, putrescine, tryptamine, 2-phenylethylamine, histamine, and tyramine) were inhibited by the presence of L. plantarum and S. xylosus, and a mixture of these bacteria had the highest inhibitory effect. Niu et al. (2019) selected L. plantarum PL-ZL001 from four types of fermented meat products and added it to sausage. PL-ZL001 inhibited the accumulation of six BAs, and its inhibitory effect on the most toxic histamine was significantly greater than that of commercial S. xylosus.

Reducing the nitrite content. Wang et al. (2013) inoculated L. sakei as a starter culture into Sichuan sausage. The results showed that the nitrite content in the sausage containing added L. sakei decreased rapidly from 100 to $9.6 \mathrm{ppm}$, whereas the nitrite content in the naturally fermented sausage decreased slowly from 100 to $32.1 \mathrm{ppm}$. You et al. (2015) inoculated lactic acid bacteria into dried salted fish as a starter, and the results showed that the mass fraction of nitrite in the dried salted fish with added lactic acid bacteria was $(0.1 \pm 0.04) \mathrm{mg} \cdot \mathrm{kg}^{-1}$, which was significantly lower than that in the group without the addition of lactic acid bacteria at $(0.8 \pm 0.04) \mathrm{mg} / \mathrm{kg}^{-1}$. Lactic acid bacteria had an inhibitory effect on the formation of nitrosamines. Gao et al. (2014) inoculated $5 \log \mathrm{CFU} / g$ and $7 \log \mathrm{CFU} / g$ L. sakei C2 into sausage, and the results showed that the nitrite content decreased with increasing inoculation concentrations.

Microorganisms can improve the quality of fermented meat products to a certain extent. They can not only promote the degradation of protein and fat and accelerate the formation of flavor substances but can also improve the nutritional value of fermented meat products. At the same time, they can inhibit the growth and reproduction of harmful bacteria, reduce the use of salt in fermented meat products, improve the taste, 
reduce the content of nitrite and BAs, and improve the safety of fermented meat products.

\section{MICROBIAL DIVERSITY IN FERMENTED MEAT PRODUCTS}

\section{Ham}

Ham is a non-ready-to-eat meat product made from fresh (frozen) pig hind legs as the primary raw material with other auxiliary materials add after finishing, curing, washing, desalting, air-drying and fermentation, and other processes. The most famous Chinese-style hams are Jinhua, Rugao, and Xuanwei hams. Alcohols, ketones, aldehydes, esters, alkanes, and acids are considered the primary volatile compounds in hams (Radovčić et al., 2016; Liu D. Y. et al., 2020; Wu et al., 2020). There is a close relationship between the staphylococci and the aldehyde compounds produced as hexanal, nonanal, benzaldehyde, and phenylacetaldehyde, indicating their contributions to the formation of characteristic flavor substances in Jinhua dry-cured ham (Wang Y. B. et al., 2021). Yeasts and molds were primarily present on the surface of Anfu ham, and cocci and yeasts were primarily present inside the ham (Huang et al., 2003). During the dehydration of Jinhua ham, the number of microorganisms inside the ham reached $1.39 \times 10^{6} \mathrm{CFU} / \mathrm{g}$, and during the maturation stage, the number of microorganisms inside decreased to $2.0 \times 10^{3} \mathrm{CFU} / \mathrm{g}$. Lactic acid bacteria and staphylococci are the dominant bacteria in Jinhua ham. The lactic acid bacteria have primarily been identified as Pediococcus urinaeequi (P. urinaeequi), Pediococcus pentosaceus ( $P$. pentosaceus), and Lactiplantibacillus pentosus (L. pentosus). The staphylococci species primarily include S. xylosus, Staphylococcus equus (S. equus) and Staphylococcus gallinarum (S. gallinarum) (He et al., 2007). The dominant microorganisms in Xuanwei ham were micrococci, staphylococci and molds, the number of which reached greater than $10^{6} \mathrm{CFU} / \mathrm{g}$ on the surface and greater than $10^{2} \mathrm{CFU} / \mathrm{g}$ inside (Li et al., 2003). Twenty-seven fungi were detected in Xuanwei ham using PCR-DGGE technology. The primary species were Aspergillus pseudoglaucus (A. pseudoglaucus), Phialosimplex caninus ( $P$. caninus), Aspergillus penicillioides (A. penicillioides), Yamadazyma triangularis (Y. triangularis), Wallemia sebi (W. sebi), and Candida glucosophila (C. glucosophila), among which the dominant fungus was A. pseudoglaucus (Zou et al., 2020). The diversity and abundance of bacteria in Panxian ham were higher than those of fungi. Ten bacterial phyla were detected at the phylum level, of which Firmicutes and Proteobacteria were dominant. Firmicutes and Proteobacteria were the dominant phyla in the curing process, while Proteobacteria was the dominant phylum in the maturing process. A total of 154 bacterial genera was detected at the genus level, and the dominant genera were Psychrobacter, Acinetobacter, Ochrobactrum, Staphylococcus, and Micrococcus. Four fungal phyla were detected at the phylum level, and the dominant fungus was Ascomycota. Fifty-one fungal genera were detected at the genus level, and the dominant fungi were Debaryomyces, Aspergillus, Yamadazyma, Candida, and Penicillium (Mu et al., 2019). After isolation and purification of the dominant microorganisms in Weining ham, a total of 10 strains was obtained, including 4 strains of Staphylococcus equinosus (S. equinosus), 2 strains of S. xylosus, 2 strains of Lactococcus lactis, 1 strain of Candida metapsilosis (C. metapsilosis), and 1 strain of Candida parapsilosis (C. parapsilosis) (Zhang et al., 2019). Among the different processing procedures of Nuodeng ham, the bacterial diversity at the salting stage was the highest, and the dominant bacteria at the phylum level were Firmicutes, Proteobacteria, Actinobacteria, and Bacteroidetes. At the genus level, the dominant bacteria included Psychrobacter, Aeromonas, Shewanella, Pseudomonas, and Acinetobacter (Wang X. R. et al., 2021). The primary species of microorganisms in different hams are presented in Table 1.

\section{Sausage}

Sausage is a type of non-ready-to-eat meat product made from fresh (frozen) livestock and poultry meat and other auxiliary materials by cutting (or mincing), stirring, curing, filling (or shaping), drying by baking (or drying in the sun, air-drying in the shade), smoking (or not smoking) and other processes. Sausage is primarily produced in Sichuan, Guangdong, Guangxi, Hunan, and Shanghai. The most famous sausages are Cantoneseand Sichuan-style sausages. Sichuan-style sausage is spicy and hot, whereas Cantonese-style sausage is salty and sweet. Among the different styles, Sichuan sausage is distinguished by its high processing and consumption, multiflavored nature and excellent flavor. The flavor components of mature sausage primarily include acetic acid, 3-hydroxy-2-butanone, 2-butanone, esters, volatile phenols, aldehydes and small amounts of alkene, and nitrogen compounds (Hu et al., 2020). Firmicutes, Proteobacteria, Actinobacteria, and Bacteroidetes were detected at the phylum level in Sichuan sausage. Firmicutes

TABLE 1 | Primary microorganisms in different hams.

\begin{tabular}{|c|c|c|}
\hline Type of ham & Primary microorganisms & References \\
\hline Anfu ham ${ }^{1}$ & $\begin{array}{l}\text { Skin coat: yeasts, molds } \\
\text { Interior: cocci, yeasts }\end{array}$ & Huang et al., 2003 \\
\hline Jinhua ham ${ }^{1}$ & $\begin{array}{l}\text { P. urinaeequi, P. pentosaceus, } \\
\text { L. pentosus, S. xylosus, } \\
\text { S. equus, S. gallinarum }\end{array}$ & He et al., 2007 \\
\hline Xuanwei ham² & $\begin{array}{l}\text { A. pseudoglaucus, P. caninus, } \\
\text { A. penicillioides, Y. triangularis, } \\
\text { W. sebi, C. glucosophila }\end{array}$ & Zou et al., 2020 \\
\hline Panxian ham² & $\begin{array}{l}\text { Psychrobacter, Acinetobacter, } \\
\text { Ochrobactrum, } \\
\text { Staphylococcus, Micrococcus, } \\
\text { Debaryomyces, Aspergillus, } \\
\text { Yamadazyma, Candida, } \\
\text { Penicilliums }\end{array}$ & Mu et al., 2019 \\
\hline Weining ham² & $\begin{array}{l}\text { S. equorum, S. xylosus, } \\
\text { P. acidilactici, C. metapsilosis, } \\
\text { C. parapsilosis }\end{array}$ & Zhang et al., 2019 \\
\hline Nuodeng ham² & $\begin{array}{l}\text { Psychrobacter, Aeromonas, } \\
\text { Shewanella, Pseudomonas, } \\
\text { Acinetobacter }\end{array}$ & Wang X. R. et al., 202 \\
\hline
\end{tabular}

${ }^{1}$ Represents the identification of microorganisms by pure culture, and ${ }^{2}$ represents the identification of microorganisms by molecular biological methods (same below). 
(85.65 93.96\%) and Proteobacteria (5.59 13.95\%) were the dominant phyla. Lactobacillus, Weissella, Brochothrix, Pediococcus, and Staphylococcus were detected at the genus level. Among them, Weissella (26.74\%) and Lactobacillus (63.14\%) were the dominant genera. Ninety percent of the fungi in Sichuan sausage were unclassified, and only Bangiales and Ascomycota exceeded $0.1 \%$ at the phylum level. Porphyra (10.75\%) was dominant at the genus level, and Debaryomyces and Saccharomyces accounted for less than 0.1\% (Wang et al., 2019). Nineteen strains of staphylococci and 12 strains of lactic acid bacteria were isolated from Cantonese sausage. According to PCR-DGGE identification, the primary dominant bacteria were Staphylococcus saprophyticus (S. saprophyticus), S. xylosus and Lactobacillus, whereas the secondary dominant bacteria were S. epidermidis, Staphylococcus cohnii (S. cohnii), Lactococcus garvieae (L. garvieae), and Bacillus spp. (Xie et al., 2013). At the phylum level, Firmicutes (57.01\%), Proteobacteria (30.43\%), Cyanobacteria (7.67\%), Bacteroidetes $(2.63 \%)$, and Actinobacteria (2.01\%) were present in Hubei Enshi sausage, among which Firmicutes and Proteobacteria were the dominant phyla. At the genus level, Brochothrix (38.34\%), Staphylococcus (9.79\%), Psychrobacter (7.55\%), Photobacterium (5.90\%), Pseudomonas (4.82\%), Lactobacillus (2.80\%), Leuconostoc (2.29\%), and Acinetobacter (2.19\%) were identified, among which Brochothrix was the dominant genus (Deng et al., 2018). Scholars have studied 16 types of traditional Chinese sausages and found that Firmicutes is the dominant phylum in most sausages. In addition, Lactobacillus, Micrococcus, Psychrobacter, Tetragenococcus, and Pseudomonas were the dominant genera. The dominant fungal phylum was Ascomycota (Li et al., 2019). Studies have shown that the dominant phyla in five types of northeast sausage are Firmicutes and Proteobacteria, whereas Lactobacillus, Staphylococcus, Leuconostoc, Lactococcus, and Weissella are the dominant genera. The dominant species are S. xylosus, L. sakei, W. hellenica, Leuconostoc citreum (L. citreum), Lactococcus raffinolactis (L. raffinolactis), and L. plantarum ( $\mathrm{Hu}$ et al., 2020). The primary species of microorganisms in different sausages are presented in Table 2.

\section{Preserved Meat}

Preserved meat is a type of non-ready-to-eat meat product made from fresh (frozen) livestock meat as the primary raw material, along with other auxiliary materials by curing, drying by baking (or drying in the sun, air-drying in the shade), smoking (or not smoking), and other processes. Preserved meat is primarily popular in Sichuan, Hunan, and Guangdong. Hexanal, 3-methyl butyraldehyde, 3-methyl valeraldehyde, (E)-2-octenal, octanal, linalool, nonanal, hexanoic acid, ethyl hexanoate, anisole, and acetone were the primary flavor contributors in preserved meat (Guo et al., 2020; Mao et al., 2021). The bacteria at the phylum level in Sichuan traditional preserved meat include Firmicutes, Proteobacteria, Actinobacteria, Cyanobacteria, and Bacteroidetes, and the dominant phylum is Firmicutes. At the genus level, the bacteria included Staphylococcus, Micrococcus, Acinetobacter, Psychrobacter, Pseudomonas, Brochothrix, Cupriavidus, Citrobacter, and Enterobacter, and the dominant genus was Staphylococcus. The fungi at the phylum level in Sichuan traditional preserved meat include Ascomycota,
TABLE 2 | Primary microorganisms in different sausages.

\begin{tabular}{|c|c|c|}
\hline Type of sausage & Primary microorganisms & References \\
\hline $\begin{array}{l}\text { Sichuan-style } \\
\text { sausage }^{2}\end{array}$ & $\begin{array}{l}\text { Lactobacillus, Weissella, } \\
\text { Brochothrix, Pediococcus, } \\
\text { Staphylococcus, Porphyra, } \\
\text { Debaryomyces, } \\
\text { Saccharomyces }\end{array}$ & Wang et al., 2019 \\
\hline $\begin{array}{l}\text { Cantonese-style } \\
\text { sausage }^{2}\end{array}$ & $\begin{array}{l}\text { S. saprophyticus, S. xylosus, } \\
\text { S. epidermidis, S. cohnii, } \\
\text { L. garvieae, Bacillus spp. }\end{array}$ & Xie et al., 2013 \\
\hline Enshi sausage $^{2}$ & $\begin{array}{l}\text { Brochothrix, Staphylococcus, } \\
\text { Psychrobacter, } \\
\text { Photobacterium, } \\
\text { Pseudomonas, Lactobacillus, } \\
\text { Leuconostoc, Acinetobacter }\end{array}$ & Deng et al., 2018 \\
\hline $\begin{array}{l}16 \text { types of } \\
\text { traditional sausage }^{2}\end{array}$ & $\begin{array}{l}\text { Micrococcus, Psychrobacter, } \\
\text { Tetragenococcus, } \\
\text { Pseudomonas, Debaryomyces, } \\
\text { Wallemia, Aspergillus }\end{array}$ & Li et al., 2019 \\
\hline $\begin{array}{l}\text { Sausages from } \\
\text { Northeast China }{ }^{2}\end{array}$ & $\begin{array}{l}\text { S. xylosus, L. sakei, } \\
\text { W. hellenica, L. citreum, } \\
\text { L. raffinolactis, L. plantarum }\end{array}$ & Hu et al., 2020 \\
\hline
\end{tabular}

2 Represents the identification of microorganisms by molecular biologica methods.

Basidiomycota, Glomeromycota, and Rozellomycota, and the dominant phylum was Ascomycota. At the genus level, Aspergillus, Debaryomyces, Candida, Wallemia, Penicillium, Malassezia, and Didymella were dominant, and the dominant fungus was Aspergillus (Wen et al., 2020). The dominant microorganisms during the shelf life of Sichuan preserved meat were Staphylococcus and Micrococcus followed by Lactobacillus (Quan et al., 2017). At the phylum level, the microorganisms in Hubei Enshi preserved meat primarily included Firmicutes (54.05\%) and Proteobacteria (44.28\%), while at the genus level, the microorganisms were primarily Staphylococcus (40.18\%), Psychrobacter (24.02\%), Pseudoalteromonas (9.37\%), Brochothrix (8.53\%), Cobetia (4.71\%), and Acinetobacter (2.31\%) (Deng et al., 2018). The number of yeasts and molds in Xiangxi preserved meat in Hunan Province reached $2.6 \times 10^{7} \mathrm{CFU} / \mathrm{g}$. The number of staphylococci and micrococci reached $3.7 \times 10^{6} \mathrm{CFU} / \mathrm{g}$. The number of lactic acid bacteria reached $2.4 \times 10^{6} \mathrm{CFU} / \mathrm{g}$, and the number of heat-resistant microorganisms reached $3.5 \times 10^{3} \mathrm{CFU} / g$ (Dong et al., 2018). A study on the microbial diversity of preserved meats in Hunan Province found that the microorganisms included approximately 20 phyla, among which Firmicutes, Proteobacteria, Cyanobacteria, and Actinobacteria were the dominant phyla. In addition, there were more than 10 microbial genera, among which Staphylococcus, Sphingomonas, Pseudomonas, Enterobacter, and Leuconostoc were the dominant genera (Yi et al., 2017). The lactic acid bacteria in Longxi preserved meat included L. plantarum, Latilactobacillus curvatus (L. curvatus), L. sakei, Companilactobacillus alimentarius (C. alimentarius), $P$. pentosaceus, and Leuconostoc mesenteroides (L. mesenteroides), of which L. plantarum has strong acid production capacity and is quite tolerant to sodium chloride and sodium nitrite (Deng et al., 2019). The total microbial number in Jilin Changchun preserved meat was $2.863 \times 10^{7} \mathrm{CFU} / \mathrm{g}$. At the genus level, before 
air drying, the dominant microorganisms included Bacillus, Acinetobacter, and Halospirulina. After air drying for 1 week, the dominant microorganisms were Pseudomonas, Acinetobacter, Psychrobacter, and Halospirulina. After air drying for 2 weeks, the dominant microorganisms were Erwinia, Halospirulina, Enterobacter, and Acinetobacter. After air drying for 3 weeks, the dominant microorganisms included Bacillus, Halospirulina, Enterobacter, and Erwinia. After air drying for 4 weeks, the dominant microorganisms were Halospirulina, Acinetobacter, Enterobacter, and Microbacteriaceae (Li et al., 2020). The primary microorganisms species in different preserved meats are presented in Table 3.

\section{Pressed Salted Duck}

Pressed salted duck is a non-ready-to-eat meat product made from duck as the raw material processed by slaughter, hair removal, evisceration, cleaning and curing, shaping, and air drying. Pressed salted duck is a specialty of the southwest region, and famous products include Chongqing Baishiyi pressed salted duck, Nanan pressed salted duck, and Jianchang pressed salted duck. Benzaldehyde and (E, E)-2,4-nonadienal are the key flavor compounds of pressed salted duck. Hexanal, nonanal, naphthalene, (Z)-2-heptenal, (E)-2-octenal, (E)-2kunienal, 1-octene-3-ol, 2-n-pentylfuran and linalool were the primary compounds affecting the flavor differences in pressed salted ducks from different regions (Tong et al., 2018). The total number of microbial colonies in Sichuan air-dried ducks was $4.692 \times 10^{3} \mathrm{CFU} / \mathrm{g}$, and Neisseria, Micrococcus, and Staphylococcus were the primary dominant genera (Liu et al., 2007). The beneficial microorganisms in Jianchang pressed salted duck primarily include staphylococci, lactic acid bacteria,

TABLE 3 | Primary microorganisms in different preserved meats.

\begin{tabular}{|c|c|c|}
\hline $\begin{array}{l}\text { Type of } \\
\text { preserved } \\
\text { meat }\end{array}$ & Primary microorganisms & References \\
\hline $\begin{array}{l}\text { Sichuan } \\
\text { preserved } \\
\text { meat }^{2}\end{array}$ & $\begin{array}{l}\text { Staphylococcus, Micrococcus, } \\
\text { Acinetobacter, Psychrobacter, } \\
\text { Pseudomonas, Brochothrix, } \\
\text { Cupriavidus, Citrobacter, } \\
\text { Enterobacter, Aspergillus, } \\
\text { Debaryomyces, Candida, } \\
\text { Wallemia, Penicillium, } \\
\text { Malassezia, Didymella }\end{array}$ & $\begin{array}{l}\text { Wen et al., 2020; Quan } \\
\text { et al., } 2017\end{array}$ \\
\hline $\begin{array}{l}\text { Enshi } \\
\text { preserved } \\
\text { meat }^{2}\end{array}$ & $\begin{array}{l}\text { Staphylococcus, } \\
\text { Psychrobacter, } \\
\text { Pseudoalteromonas, } \\
\text { Brochothrix, Cobetia, } \\
\text { Acinetobacter }\end{array}$ & Deng et al., 2018 \\
\hline $\begin{array}{l}\text { Hunan } \\
\text { preserved } \\
\text { meat }^{1}\end{array}$ & $\begin{array}{l}\text { Staphylococcus, } \\
\text { Sphingomonas, Pseudomonas, } \\
\text { Enterobacter, Leuconostoc }\end{array}$ & Yi et al., 2017 \\
\hline $\begin{array}{l}\text { Longxi } \\
\text { preserved } \\
\text { meat }^{1}\end{array}$ & $\begin{array}{l}\text { L. plantarum, L. curvatus, } \\
\text { L. sakei, C. alimentarius, } \\
\text { P. pentosaceus, } \\
\text { L. mesenteroides }\end{array}$ & Deng et al., 2019 \\
\hline
\end{tabular}

${ }_{1}^{1}$ Represents the identification of microorganisms by pure culture, and ${ }^{2}$ represents the identification of microorganisms by molecular biological methods. micrococci, yeasts, and molds. The staphylococci include S. carnosus, Staphylococcus simulans (S. simulans), and S. xylosus. The lactic acid bacteria include Lactobacillus [L. plantarum, L. sakei, Lactobacillus acidophilus (L. acidophilus), L. lactis, Lacticaseibacillus casei (L. casei), L. curvatus, Limosilactobacillus fermentum (L. fermentum), Loigolactobacillus bifermentans (L. bifermentans), Levilactobacillus brevis (L. brevis), Lentilactobacillus buchneri subsp. buchneri (L. buchneri), Lactobacillus helveticus (L. helveticus), and Lactobacillus delbrueckii subsp. bulgaricus (L. delbrueckii)], Streptococcus [Streptococcus lactis (S. lactis), Streptococcus acidilactis (S. acidilactis), Streptococcus diacetilactis ( $S$. diacetilactis)] and Pediococcus [Pediococcus acidilactici (P. acidilactici), $P$. pentosaceus, and Pediococcus cerevisiae ( $P$. cerevisiae)]. The micrococci include Micrococcus auterisiae (M. auterisiae), Micrococcus candidus ( $M$. candidus), Micrococcus varians (M. varians), Micrococcus roseus (M. roseus), Micrococcus epidermidis (M. epidermidis), and M. luteus (Lin, 2017). The predominant spoilage bacteria in water-cooked salted duck at the end of the shelf life were Brochothrix thermosphacta (B. thermosphacta) and lactic acid bacteria, and minor components were enterobacteriaceae, micrococci, yeasts and molds (Li et al., 2010). The primary species of microorganisms in different pressed salted ducks are presented in Table 4.

\section{Preserved Fish}

Preserved fish are made from fresh fish that are processed by slaughter and scale removal, evisceration, curing, and drying by baking (or drying in the sun, air-drying in the shade). Preserved fish are characterized by their unique flavor and storage stability (Hu and Wang, 2018). The volatile flavor compounds in traditional preserved fish are primarily aldehydes, alcohols and heterocyclic compounds.

TABLE 4 | Primary microorganisms in different pressed salted ducks.

\begin{tabular}{lll}
\hline $\begin{array}{l}\text { Type of pressed } \\
\text { salted duck }\end{array}$ & Primary microorganisms & References \\
\hline
\end{tabular}

\begin{tabular}{lll}
\hline Sichuan air-dried & Neisseria, Micrococcus, & Liu et al., 2007 \\
duck ${ }^{1}$ & Staphylococcus & Lin, 2017 \\
JianChang pressed & S. carnosus, S. simulans, & \\
salted duck ${ }^{2}$ & S. xylosus, L. plantarum, & L. sakei, L. acidophilus, \\
& L. lactis, L. casei, L. curvatus, \\
& L. fermentum, L. bifermentans, \\
& L. brevis, L. buchneri, \\
& L. helveticus, L. delbrueckii., \\
& S. lactis, S. acidilactis, \\
& S. diacetilactis, P. acidilactici, \\
& P. pentosaceus, P. cerevisiae, \\
& M. auterisiae, M. candidus, M. \\
& varians, M. roseus, \\
M. epidermidis, M. luteus, & \\
& yeasts, molds
\end{tabular}

Water-cooked salted duck ${ }^{1}$

B. thermosphacta, lactic acid

Li et al., 2010 bacteria, enterobacteriaceae, micrococci, yeasts, molds

${ }^{1}$ Represents the identification of microorganisms by pure culture, and ${ }^{2}$ represents the identification of microorganisms by molecular biological methods. 
Among them, hexanal, caprylic aldehyde, nonyl aldehyde, 2-non-ene aldehyde, decanal, 3-methyl butyraldehyde, (z)-4heptylaldehyde, benzaldehyde, 1-octene-3-ol, 1-pentene-3-ol, 3-methyl butanol, heptanol, trimethylamine, and 3-methyl$1 \mathrm{H}$-indole are the primary active substances ( $\mathrm{Gu}$ et al., 2019; Xu et al., 2020; Zhang et al., 2020). Microbes at the phylum level in Enshi-preserved fish from Hubei included Proteobacteria (61.29\%), Firmicutes (30.21\%), Bacteroidetes (5.34\%), and Actinobacteria (1.74\%). At the genus level, the primary genera included Psychrobacter (35.70\%), Brochothrix (19.74\%), Pseudomonas (7.13\%), Staphylococcus (7.12\%), Acinetobacter (4.19\%), Vibrio (3.90\%), Pseudoalteromonas (3.09\%), and Chryseobacterium (1.98\%) (Wang et al., 2018). Zeng et al. (2009) found that the dominant microorganisms during the processing of preserved fish were lactic acid bacteria, micrococci, staphylococci, and yeasts. The dominant microorganisms at the phylum level during the processing of dried preserved fish included Bacteroidetes, Firmicutes and Proteobacteria. At the family level, the dominant microorganisms largely included Xanthomonadaceae, Comamonadaceae, Campylobacteraceae, Clostridiaceae, Lacto bacteriaceae, Vibrionaceae, Streptococcaceae, Aeromonadaceae, Moraxellaceae, Planococcaceae, Shewanellaceae, Entero coccaceae, Pseudomonadaceae, Staphylococcaceae, Bacillaceae, and Enterobacteriaceae (Wu et al., 2017). The primary species of microorganisms in different preserved fish are presented in Table 5.

\section{Air-Dried Meat}

Air-dried meat is stored at temperatures below zero. The meat is cut into small strips and treated with spices, pickled and hung

TABLE 5 | Primary microorganisms in different preserved fish.

\begin{tabular}{|c|c|c|}
\hline Type of preserved fish & Primary microorganisms & References \\
\hline Enshi preserved fish ${ }^{2}$ & $\begin{array}{l}\text { Psychrobacter, Brochothrix, } \\
\text { Pseudomonas, } \\
\text { Staphylococcus, } \\
\text { Acinetobacter, Vibrio, } \\
\text { Pseudoalteromonas, } \\
\text { Chryseobacterium }\end{array}$ & Wang et al., 2018 \\
\hline Preserved fish ${ }^{2}$ & $\begin{array}{l}\text { Lactic acid bacteria, } \\
\text { micrococci, staphylococci, } \\
\text { yeasts }\end{array}$ & Zeng et al., 2009 \\
\hline Salted dried fish ${ }^{2}$ & $\begin{array}{l}\text { Xanthomonadaceae, } \\
\text { Comamonadaceae, } \\
\text { Campylobacteraceae, } \\
\text { Clostridiaceae, } \\
\text { Lactobacteriaceae, } \\
\text { Vibrionaceae, } \\
\text { Streptococcaceae, } \\
\text { Aeromonadaceae, } \\
\text { Moraxellaceae, } \\
\text { Planococcaceae, } \\
\text { Shewanellaceae, } \\
\text { Enterococcaceae, } \\
\text { Pseudomonadaceae, } \\
\text { Staphylococcaceae, } \\
\text { Bacillaceae, } \\
\text { Enterobacteriaceae }\end{array}$ & Wu et al., 2017 \\
\hline
\end{tabular}

${ }^{2}$ Represents the identification of microorganisms by molecular biologica methods.
TABLE 6 | Primary microorganisms in different air-dried meat.

\begin{tabular}{lll}
\hline $\begin{array}{l}\text { Type of air-dried } \\
\text { meat }\end{array}$ & Primary microorganisms & References \\
\hline $\begin{array}{l}\text { Xinjiang air-dried } \\
\text { beef }^{1}\end{array}$ & $\begin{array}{l}\text { Lactic acid bacteria, } \\
\text { staphylococci, micrococci, } \\
\text { enterobacteria, } \\
\text { pseudomonades, enterococci, } \\
\text { molds, yeasts, cocci }\end{array}$ & $\begin{array}{l}\text { Wang et al., 2016; } \\
\text { Lei et al., 2017 }\end{array}$ \\
$\begin{array}{l}\text { Naturally fermented } \\
\text { air-dried meat }{ }^{2}\end{array}$ & $\begin{array}{l}\text { Firmicutes, Proteobacteria, } \\
\text { Bacteroidetes }\end{array}$ & Tian et al., 2019 \\
\hline
\end{tabular}

${ }^{1}$ Represents the identification of microorganisms by pure culture, and ${ }^{2}$ represents the identification of microorganisms by molecular biological methods.

in the shade, and it is naturally air-dried for approximately 3 months to form a directly edible product. After drying, the meat is crispy, and this product is commonly found in Xizang and northwestern Inner Mongolia. The volatile flavor compounds in air-dried meat include acids, aldehydes, ketones, alcohols, alkenes, sulfur-containing compounds and heterocyclic compounds, among which heptanal, 1octene-3-ol, cyclopentanol, 3-hydroxy-2-heptanone, and 6-methyl-5-heptene-2-ketone are the primary contributors (Ma et al., 2021). The dominant microorganisms during the air-drying process of Xinjiang air-dried beef were lactic acid bacteria, staphylococci and micrococci. The total number of microorganisms was $8.0 \times 10^{8} \mathrm{CFU} / \mathrm{g}$, the number of lactic acid bacteria was $1.48 \times 10^{7} \mathrm{CFU} / \mathrm{g}$, the number of staphylococci and micrococci was approximately $4.40 \times 10^{8} \mathrm{CFU} / \mathrm{g}$, the number of enterobacteria was approximately $10^{2} \mathrm{CFU} / \mathrm{g}$, the number of enterococci was less than $10^{5} \mathrm{CFU} / \mathrm{g}$, and the number of yeasts and molds was approximately $1.50 \times 10^{4} \mathrm{CFU} / \mathrm{g}$ (Wang et al., 2016). Lei et al. (2017) found $36 \%$ enterobacteria, $33 \%$ yeasts, $16 \%$ pseudomonades, $10 \%$ cocci, and 5\% lactic acid bacteria in Xinjiang air-dried beef. In naturally fermented air-dried meat, 21 microbial phyla and 241 microbial genera were detected, and the dominant phyla included Firmicutes (39\%), Proteobacteria (40\%), and Bacteroidetes (14\%) (Tian et al., 2019). The primary species of microorganisms in different air-dried meat samples are presented in Table 6.

\section{CONCLUSION AND PROSPECT}

Due to differences in raw materials, technology, auxiliary materials and fermentation time, the microbial species in fermented meat products in China are different. However, most fermented meat products in China are subjected to salting and fermentation, so the microbial compositions share some similarities. Microorganisms in fermented meat products mainly include staphylococci, lactobacilli, micrococci, yeasts, and molds.

At present, research on fermented meat products largely focuses on the microbial diversity of fermented meat products, the mechanisms by which specific microbes influence the quality of fermented meat products, the characteristic flavor of fermented meat products and their production pathway. A large number of studies have shown that microorganisms can promote the formation flavor of fermented meat products and inhibit the 
generation of BAs, nitrosamines and other harmful chemicals in fermented meat products, but the specific mechanisms have not been fully reported. In the future, research on these mechanisms will provide effective theoretical support for improving the production process and the modernization and standardization of production of fermented meat products.

\section{AUTHOR CONTRIBUTIONS}

ZLW and ZXW conducted the literature collection and literature research. ZLW drafted the original manuscript. ZLW, ZXW, and LC modified the manuscript. All authors critically reviewed, contributed to, and approved the final manuscript.

\section{REFERENCES}

Chen, Q., Kong, B. H., Han, Q., Xia, X. F., and Xu, L. (2017). The role of bacterial fermentation in lipolysis and lipid oxidation in Harbin dry sausages and its flavour development. LWT Food Sci. Technol. 77, 389-396. doi: 10.1016/j.lwt. 2016.11.075

Deng, F., Wang, Y. R., Shang, X. J., She, M. N., Ge, D. Y., Zhao, H. J., et al. (2018). Bacterial diversity of sausages in Enshi of Hubei province. Meat Res. 32, 18-22. doi: 10.7506/rlyj1001-8123-201809004

Deng, Z. R., Yun, J. M., Guo, J., Niu, Y. X., and Li, Y. H. (2019). Study on isolation and fermentation performance of dominant lactic acid bacteria during the processing of Longxi Bacon. Curr. Biotechnol. 9, 200-209. doi: 10.19586/j.20952341.2018.0098

Dong, Y., Wang, Y. R., Wang, Y., Liao, H., Zhao, H. J., and Guo, Z. (2018). Evaluation of bacterial diversity in Chinese bacon from enshi by denatured gradient gel electrophoresis and MiSeq high-throughput sequencing. Meat Res. 32, 37-42. doi: 10.7506/rlyj1001-8123-201810007

Douglas, P., Erick, S., Manuel, L. J., Mirian, P., Ruben, D., Alves, D. S. B., et al. (2020). Low-sodium dry-cured rabbit leg: a novel meat product with healthier properties. Meat Sci. 173:108372. doi: 10.1016/j.meatsci.2020.108372

Frédéric, L., Jurgen, V., and Luc, D. V. (2006). Functional meat starter cultures for improved sausage fermentation. Intern. J. Food Microbiol. 106, 270-285.

Gao, Y. R., Li, D. P., and Liu, X. Y. (2014). Bacteriocin-producing Lactobacillus sakei $\mathrm{C} 2$ as starter culture in fermented sausages. Food Control 35, 1-6. doi: 10.1016/j.foodcont.2013.06.055

Gu, S. Q., Tang, J. J., Zhou, X. X., Zheng, H. M., Zhou, H. X., and Ding, Y. T. (2019). Quality change and aroma formation in cured fish during traditional sun drying processing. Food Sci. 40, 36-44. doi: 10.7506/spkx1002-6630-20180716-201

Guo, J., Wang, Q., Chen, C. G., Yu, H., and Xu, B. (2020). Effects of different smoking methods on sensory properties, free amino acids and volatile compounds in bacon. J. Sci. Food Agric. 101, 2984-2993. doi: 10.1002/jsfa.10931

He, G. Q., Liu, T. J., Sadiq, F. A., Gu, J. S., and Zhang, G. H. (2017). Insights into the microbial diversity and community dynamics of Chinese traditional fermented foods from using high-throughput sequencing approaches. J. Zhejiang Univ. Sci. B 18, 289-302. doi: 10.1631/jzus.B1600148

He, Z. F., Li, H. Y., Yu, X., Zhou, R. H., and Zhang, M. (2007). Study on the changes in microbial flora of jinhua ham in modern fermentation technology. J. Southwest Univ . 29, 142-150. doi: 10.3969/j.issn.1673-9868.2007.03.030

$\mathrm{Hu}, \mathrm{D}$., and Wang, M. (2018). Research on processing technology of Chinese traditional preserved fish. Technol. Econ. Guide 26:61.

Hu, Y. Y., Zhang, L., Liu, Q., Wang, Y., Chen, Q., and Kong, B. H. (2020). The potential correlation between bacterial diversity and the characteristic volatile flavour of traditional dry sausages from Northeast China. Food Microbiol. 91:103505. doi: 10.1016/j.fm.2020.103505

Huang, Z. W., Xu, M. S., Tang, K. J., Jiang, Y., and Wu, S. F. (2003). Separation of fermentation microorganism in Aufu Ham and its fermentation technology. Acta Agric. Univ. Jiangxien. 25, 635-638. doi: 10.3969/j.issn.1000-2286.2003.04. 037

\section{FUNDING}

This work was supported by the Key Research and Development Program of Sichuan Province (2020YFN0147), the National Modern Agriculture Industry Technology System (SCSZTD-3007), the Key Research and Development Program of Sichuan Province (2019YFN0172), and the Department of Science and Technology of Sichuan Province (2020ZYD067).

\section{ACKNOWLEDGMENTS}

We would like to thank AJE (www.aje.cn) for english language editing. We would also like to appreciate the reviewers for their constructive comments.

Lei, Y. H., Guo, J. N., Sun, B. Z., Xie, P., Zhang, Y., Li, H. B., et al. (2017). Characteristics of microbial changes in the processing of dried beef in Xinjiang. J. Food Saf. Q. 8, 2914-2921. doi: 10.3969/j.issn.2095-0381.2017.08.013

Li, J. X., Wang, W., Wang, X. H., and Bai, T. (2015). The source and formation of flavor substances in fermented sausage. Food Sci. Technol. 40, 160-165. doi: 10.13684/j.cnki.spkj.2015.05.032

Li, L., Zou, D., Ruan, L. Y., Wen, Z. Y., Chen, S. W., Xu, L., et al. (2019). Evaluation of the biogenic amines and microbial contribution in traditional Chinese sausages. Front. Microbiol. 10:872. doi: 10.3389/fmicb.2019.00872

Li, P. L., Shen, Q. W., Lv, Y. N., Jiang, Z. J., and Ma, C. W. (2003). Analysis of main of microorganisms in Xuanwei Ham. Chin. J. Microecol. 15, 12-13. doi: 10.3969/j.issn.1005-376X.2003.05.007

Li, X. R., Liu, L. Y., Yang, Y., Hou, P. P., Zhao, Y. T., Zhang, T. H., et al. (2020). Physicochemical, microbial and flavor profiles of traditional Chinese cured meat. Meat Res. 34, 22-26. doi: 10.7506/rlyj1001-8123-20190821-187

Li, Y. L., Yao, D. R., Wang, D. Y., Xu, W. M., Zhu, Y. Z., and Jin, B. Q. (2010). Sensory, physicochemical and microbiological changes in water-cooked salted duck during storage at $4^{\circ}$ C. Asian Austr. J. Anim. Sci. 23, 960-964. doi: 10.5713/ ajas. 2010.90550

Liang, J., Zhao, J. R., Ji, Y. G., Sun, S. L., and Zhan, J. F. (2010). Microbiological safety analysis of several fermented meat products. Heilongjiang Anim. Sci. Vet. Med. 52, 34-35. doi: 10.13881/j.cnki.hljxmsy.2010.22.002

Lin, Q. (2017). Jianchang Duck in the fermentation process of microorganism. Modern Food 33, 66-69. doi: 10.16736/j.cnki.cn41-1434/ts.2017.06.027

Liu, D. Y., Bai, L., Feng, X., Chen, Y. P., Zhang, D. N., Yao, W. S., et al. (2020). Characterization of Jinhua ham aroma profiles in specific to aging time by gas chromatography-ion mobility spectrometry (GC-IMS). Meat Sci. 168:108178. doi: 10.1016/J.MEATSCI.2020.108178

Liu, X., Zhang, W. X., Yue, Y. Y., Wang, W., and Yu, H. (2007). A preliminary study on the microflora of Wind-blown duck from Sichuan. Sci. Technol. Food Indust. 28, 82-87. doi: 10.3969/j.issn.1002-0306.2007.07.022

Liu, Y. L., Yu, Q. L., Wan, Z., Li, H. Y., Liu, J., and Wang, J. (2020). Research progress of antioxidant activity of starter culture on the quality of fermented meat products. Food Sci. 82, 1-17. doi: 10.7506/spkx1002-6630-202007 04-052

Ma, G. L., Tang, S. H., Li, S. N., Liu, H. L., and Ren, R. (2021). Changes of physicochemical properties and volatile flavor substances in tibetan air-dried yak meat jerky during the simulated processing. Sci. Technol. Food Industr. 42, 19-25. doi: 10.13386/j.issn1002-0306.20200301018

Mao, Y. Q., Li, Y. H., Yun, J. M., He, K., Wang, R., and Wu, S. J. (2021). Volatile flavor compounds in traditional Longxi bacon production. Food Fermentat. Industr. 47, 144-152. doi: 10.13995/j.cnki.11-1802/ts.025248

$\mathrm{Mu}$, Y., Su, W., Mu, Y. C., and Jiang, L. (2019). Combined application of high-throughput sequencing and metabolomics reveals metabolically active microorganisms during Panxian Ham processing. Front. Microbiol. 10:3012. doi: $10.3389 /$ fmicb. 2019.03012

Niu, T. J., Chen, L. S., Kong, H. G., Guo, Y. J., and Ma, Y. (2019). Screening, identification and application of biogenic amine degrading strains derived from 
traditional fermented meat products. China Brew. 38, 43-48. doi: 10.11882/j. issn.0254-5071.2019.09.009

PaPamanoli, E., Kotzekidou, P., Tzanetakis, N., and Litopoulou-Tzanetaki, E. (2002). Characterization of Mieroeoccaeeae isolated from dry fermented sausage. Food Microbiol. 19, 441-449. doi: 10.1006/fmic.2002. 0503

Polka, J., Rebecchi, A., Pisacane, V., Morelli, L., and Puglisi, E. (2015). Bacterial diversity in typical Italian salami at different ripening stages as revealed by highthroughput sequencing of 16S rRNA Amplicons. Food Microbiol. 46, 342-356. doi: 10.1016/j.fm.2014.08.023

Quan, T., Deng, D. C., Li, H. J., He, Z. F., Zhang, Y. H., and Zhang, J. X. (2017). Study on the main microorganisms of traditional Sichuan bacon during its shelf life. J. Southwest Univ. 39, 14-21. doi: 10.13718/j.cnki.xdzk.2017.02.003

Radovčić, N. M., Vidaček, S., Janči, T., and Medić, H. (2016). Characterization of volatile compounds, physico-chemical and sensory characteristics of smoked dry-cured ham. J. Food Sci. Technol. 53, 4093-4105. doi: 10.1007/s13197-0162418-2

Sivamaruthi, B. S., Kesika, P., and Chaiyasut, C. (2020). A narrative review on biogenic amines in fermented fish and meat products. J. Food Sci. Technol. 58, 1623-1639. doi: 10.1007/s13197-020-04686-X

Sun, Q. X., Chen, Q., Li, F. F., Zheng, D. M., and Kong, B. H. (2016). Biogenic amine inhibition and quality protection of Harbin dry sausages by inoculation with Staphylococcus xylosus and Lactobacillus plantarum. Food Control 68, 358-366. doi: 10.1016/j.foodcont.2016.04.021

Swetwiwathana, A., and Visessanguan, W. (2015). Potential of bacteriocinproducing lactic acid bacteria for safety improvements of traditional Thai fermented meat and human health. Meat Sci. 109, 101-105. doi: 10.1016/j. meatsci.2015.05.030

Tian, J. J., Zhang, K. P., Yang, M. Y., Jing, Z. B., Li, Q. W., Zhao, L. H., et al. (2019). Comparative bacterial diversity analysis and microbial safety assessment of airdried meat products by Illumina MiSeq Sequencing technology. Food Sci. 40, 33-40. doi: 10.7506/spkx1002-6630-20180504-043

Tong, H. G., Wang, W., Zhang, H. F., Li, P. J., Chen, C. G., and Chen, J. (2018). Comparative analysis flavor components of dry-cured ducks from different regions by HPLC, GC-MS combined with multivariate statistical analysis. Modern Food Sci. Technol. 34, 228-238. doi: 10.13982/j.mfst.1673-9078.2018. 12.034

Wang, J. G., Li, Y. H., Guo, A. M., Han, D. Y., and Liu, C. J. (2016). Physicochemical and microbial properties of Xinjiang dry-cured beef during the ripening process. Food Fermentat. Industr. 42, 129-133. doi: 10.13995/j.cnki. $11-1802 /$ ts.201610022

Wang, W., Liu, Y., Wang, X. H., and Zhang, J. M. (2014). Effects of microbial fermentation agents on the storable nature and flavor characteristics of Sichuan bacon. Food Sci. Technol. 39, 159-164. doi: 10.13684/j.cnki.spkj.2014.09.035

Wang, X. H., Ren, H. Y., Liu, D. Y., Zhu, W. Y., and Wang, W. (2013). Effects of inoculating Lactobacillus sakei starter cultures on the microbiological quality and nitrite depletion of Chinese fermented sausages. Food Control 32, 591-596. doi: 10.1016/j.foodcont.2013.01.050

Wang, X. H., Wang, S. H., and Zhao, H. (2019). Unraveling microbial community diversity and succession of Chinese Sichuan sausages during spontaneous fermentation by high-throughput sequencing. J. Food Sci. Technol. 56, 32543263. doi: 10.1007/s13197-019-03781-y

Wang, X. R., Shi, Q., Liu, B. Q., Lei, Y. D., Tang, H. H., Zhang, S. Z., et al. (2021). Bacterial dynamics during the processing of nuodeng Dry-cured Ham. Sci. Technol. Food Industry 42, 83-89. doi: 10.13386/j.issn1002-0306.2020030129

Wang, Y. B., Li, F., Chen, J., Sun, Z. H., Wang, F. F., Wang, C., et al. (2021). Highthroughput sequencing-based characterization of the predominant microbial community associated with characteristic flavor formation in Jinhua Ham. Food Microbiol. 94:103643. doi: 10.1016/J.FM.2020.103643

Wang, Y. R., Liao, H., Zhao, H. J., Zhang, Z. D., and Guo, Z. (2018). Evaluation of the bacterial diversity in cured fish samples collected from Enshi by PCRDGGE and MiSeq high-throughput sequencing. Modern Food Sci. Technol. 34, 208-213. doi: 10.13982/j.mfst.1673-9078.2018.11.031
Wen, K. Y., Wang, Y., Wen, P. C., Zhu, Y., Yang, M., Zhang, Z. M., et al. (2020). Study on microbial community structure in Sichuan traditional bacon. Food Fermentat. Industr. 46, 36-42. doi: 10.13995/j.cnki.11-1802/ts.022133

Wu, W. H., Zhou, Y., Wang, G. Y., Zhu, R. J., Ge, C. R., and Liao, G. Z. (2020). Changes in the physicochemical properties and volatile flavor compounds of dry-cured Chinese Laowo ham during processing. J. Food Process. Preserv. 44:e14593. doi: 10.1111/jfpp.14593

Wu, Y. Y., Qian, X. X., Li, L. H., Chen, S. J., Deng, J. C., and Li, C. S. (2017). Microbial community diversity in dried-salted fish during processing revealed by Illumina MiSeq sequencing. Food Sci. 38, 1-8. doi: 10.7506/spkx1002-6630201712001

Xie, K., Yu, X. F., Zheng, H. S., Zong, K., Lian, Y. Q., and Liu, G. Q. (2013). Analysis of dominant microbial species in cantonese sausage by independent culture and PCR-DGGE technology. Food Sci. 34, 157-160.

Xu, Y. S., Zang, J. H., Regenstein, J. M., and Xia, W. S. (2020). Technological roles of microorganisms in fish fermentation: a review. Critic. Rev. Food Sci. Nutr. 61, 1000-1012. doi: 10.1080/10408398.2020.1750342

Yi, L. B., Su, G. R., Hu, G., and Peng, Q. Z. (2017). Diversity study of microbial community in bacon using metagenomic analysis. J. Food Saf. 37:e12334. doi: $10.1111 /$ jfs. 12334

You, G., Wu, Y. Y., Li, L. H., Yang, X. Q., Qi, B., and Chen, S. J. (2015). Effect of inoculating compound lactic acid bacteria on microbial,nitrites and nitrosamines of salted fish. South China Fish. Sci. 11, 109-115. doi: 10.3969/j. issn.2095-0780.2015.04.016

Yu, C. Q., Yao, D., Man, Y. G., and Wang, C. Y. (2010). Harm and control on biogenic amines of fermented meat products. Meat Res. 31, 41-45. doi: 10.3969/ j.issn.1001-8123.2010.01.013

Zeng, L. B., Xiong, S. B., and Wang, L. (2009). Changes in microbe quantity and physico-chemical properties during processing of cured silver carp. Food Sci. 30, 54-57. doi: 10.3321/j.issn:1002-6630.2009.03.011

Zhang, C. X., He, Z. F., and Li, H. J. (2017). Research of bacteriocins from lactic acid bacteria and their applications in preservation of meat products. Food Fermentat. Industr. 43, 271-277. doi: 10.13995/j.cnki.11-1802/ts.013971

Zhang, Q., Ding, Y. C., Gu, S. Q., Zhu, S. C., Zhou, X. X., and Ding, Y. T. (2020). Identification of changes in volatile compounds in dry-cured fish during storage using HS-GC-IMS. Food Res. Intern. 137:109339. doi: 10.1016/J.FOODRES. 2020.109339

Zhang, S. Y., Tang, N., Huang, P., Zhou, Y., Xu, B. C., and Li, P. J. (2019). Isolation, identification and tolerance characteristics of microorganisms from Weining Ham. Meat Res. 33, 12-17. doi: 10.7506/rlyj1001-8123-20190625-147

Zhao, D. B., Wang, L. Y., Fu, Y., Wang, J. H., Tan, C. X., Wang, M. M., et al. (2017). Study on strain screening, identification and physical and chemical properties characteristics of bacteriocin- producing lactic acid bacteria in Nanjing drycured duck. Meat Industry 37, 19-23. doi: 10.3969/j.issn.1008-5467.2017.01. 007

Zhou, H. M., Zhang, S. L., Zhao, B., Li, S., Pan, X. Q., Ren, S., et al. (2018). Effect of starter culture mixture of Staphylococcus xylosus and S. carnosus on the quality of dry-cured meat. Food Sci. 39, 32-38. doi: 10.7506/spkx1002-6630-201822006

Zou, Y. L., Liu, S. Y., Wang, G. Y., Pu, Y. H., Ge, C. G., and Liao, G. Z. (2020). Analysis of fungal community structure in Xuanwei ham by PCR-DGGE. Food Fermentat. Industr. 46, 269-274. doi: 10.13995/j.cnki.11-1802/ts.022394

Conflict of Interest: The authors declare that the research was conducted in the absence of any commercial or financial relationships that could be construed as a potential conflict of interest.

Copyright (C) 2021 Wang, Wang, Ji, Zhang, Zhao, Zhang, Bai, Hou, Zhang, Liu, Wang and Chen. This is an open-access article distributed under the terms of the Creative Commons Attribution License (CC BY). The use, distribution or reproduction in other forums is permitted, provided the original author(s) and the copyright owner(s) are credited and that the original publication in this journal is cited, in accordance with accepted academic practice. No use, distribution or reproduction is permitted which does not comply with these terms. 